\title{
Correction to: Expression of matrix metalloproteinase 12 is highly specific for non-proliferating invasive trophoblasts in the first trimester and temporally regulated by oxygen-dependent mechanisms including HIF-1A
}

\author{
Ursula Hiden ${ }^{1}$. Christian P. Eyth ${ }^{2}$. Alejandro Majali-Martinez ${ }^{1} \cdot$ Gernot Desoye $^{1}$. Carmen Tam-Amersdorfer ${ }^{2}$. \\ Berthold Huppertz ${ }^{3} \cdot$ Nassim Ghaffari Tabrizi-Wizsy ${ }^{2}$
}

Published online: 13 December 2017

(c) Springer-Verlag GmbH Germany, part of Springer Nature 2017

\section{Correction to: Histochem Cell Biol https://doi.org/10.1007/s00418-017-1608-y}

In the original publication, the contribution of Dr. Christian Eyth as equal first author was not indicated. This has been corrected confirming that U. Hidden and C. Eyth contributed equally to this work.

Ursula Hiden and Christian P. Eyth have contributed equally to this work.

The original article can be found online at https://doi. org/10.1007/s00418-017-1608-y.

Ursula Hiden

ursula.hiden@medunigraz.at

1 Department of Obstetrics and Gynecology, Medical

University of Graz, Graz, Austria

2 Institute of Pathophysiology and Immunology, Center of Molecular Medicine, Medical University of Graz, Graz, Austria

3 Institute of Cell Biology, Histology and Embryology, Medical University of Graz, Graz, Austria 